\title{
Performance Evaluation of Public-Private Partnerships in Health Sector of Pakistan
}

\author{
Nasir Abbas \\ Institute of Business Administration, University of the Punjab, Lahore, Pakistan \\ Jafar Hussain \\ Hailey College of Business Administration, University of the Punjab, Lahore, Pakistan \\ Talat Islam \\ Institute of Business Administration, University of the Punjab, Lahore, Pakistan \\ Dr, Zeshan Ahmer \\ Institute of Business Administration, University of the Punjab, Lahore, Pakistan
}

\begin{abstract}
The current study aimed to evaluate the performance of hospitals working under public-private partnership (PPP) using Marshall and Hays model. The model of Marshall and Hays proposed five elements i.e. patient care, doctor's behavior, financial assistance, technical quality and accessibility that influence hospital performance. We adopt this model to explore the hospital's performance working under PPP in Pakistan. Data were collected from 384 patients from the hospitals working under PPP. The findings of the current study show that patient care, and accessibility of healthcare services to the patients positively influence the performance of public-private hospitals. The results of the study have significant theoretical and practical implications.
\end{abstract}

Keywords: PFI Model, public private partnership, hospital sector, technical quality

DOI: $10.7176 /$ PPAR/9-1-02

\section{Introduction}

Historically, service delivery for health care systems is controlled by governments as it is considered the prime responsibility of the government in the country. As the population is growing, the government bodies are finding it difficult to provide quality healthcare services to the masses. The cost for the delivery of appropriate health care services is also increasing. Globally, a major portion of the federal budgets are allocated for the betterment of the public health care, yet there are issues with the efficiency of the systems and the patients face problems. The government initiated several programs to improve the delivery of health care service to the general public, such as public-private partnerships. Public-private partnerships are demand-driven, market-based arrangements to satisfy unmet needs (Savas \& Savas, 2000); the arrangements are made between the government and the private sector for the betterment of public services. The funds generate under Public-private partnerships generally provide used for the construction of infrastructure, improvement of technical facilities and healthcare services.

The idea of public-private partnerships has gained popularity around the globe, majorly focusing on transportation sector and health sector. The advantage of this idea was to save investment of state in providing the facilities to the people of the country while the payback period to the investor was spread over a longer period of time. The projects of public-private partnership in healthcare sector had also faced failures. In some cases, the partners faced financial stress causing the finance issues leading to failure. Also, there were reported issues regarding service quality (Barlow, Roehrich, \& Wright, 2013).

In Pakistan, public-private partnership experiments in some sectors in last few years. The sectors participating in public-private partnership mainly include transport, road infrastructure, sports infrastructure, housing projects, wastewater treatment plants, education, and healthcare. International funding agencies are also showing interest to support the projects involving public-private partnerships e.g. Asian Development Bank. Public-private partnerships in health care are managed through the ministry of health both at federal and provincial levels. The nature of collaboration in the healthcare sector is mainly in financing and healthcare provision. The regulatory role lies with the government.

The health infrastructure of public sector institutions is deteriorating and the private sector facilities are out of budget for the common people. In Punjab, the work has started in this dimension since 2008 with the partnerships with the private sector of Turkey and NGO's. The restructuring of health facilities is already taking place within different provinces. The current research tries to evaluate the performance of few selected hospitals being run under public-private partnership using five dimensions chosen from the literature.

The primary aim of the study is to evaluate the performance of hospitals working under the public-private partnership model. The study also aims to evaluate the effect of various factors contributing towards hospital 
performance. In this regard, a model developed by Marshall and Hays (1994) has been adopted to identify the important factors that ascertain a hospital's performance. Five factors have been identified in this model, i.e. patient care, technical quality, financial aspects, doctors' behavior and accessibility.

\section{Literature Review}

Pakistan ranked as emerging economies by IMF in 2016, yet there is lack of basic facilities especially regarding education, transportation, and health. These are emerging issues in all province of Pakistan. Many people are deprived of health and education facilities. This is mainly due to overpopulation, corruption, and missmanagement that is resulted in poor performance of the public sector in the country. There are two classes of people in Pakistan; one is an elite class who enjoys the health facilities of private sector hospitals and another one is middle and lower class who are dependent on public sector health facilities. The public-private partnership is introduced to provide better facilities in the healthcare sector.

The rising demand and increased expenses for health service delivery are stressing health service delivery frameworks around the world. Tending to these difficulties is overwhelmingly an issue for governments, as most health service delivery systems today stay inside the administrative control (Sapri, Hariati, Ting, \& Sipan, 2016). By enlarge, governments' initial step is to consider how public hospitals specifically, are financed and operated, since, in most nations, public hospitals and the individual auxiliary administrations represent the major portion of healthcare spending. Intending to this issue, governments are progressively considering different models of private division support, frequently alluded to as Public-Private Partnerships (PPPs). Such courses of action progressively offer a feasible way to deal with controlling costs, improving service quality and even expanding access to the general public (Kinlaw, 2008).

A Public-Private Partnership (PPP) refers to as a legal contract/agreement between a public organization and a private sector entity in which both parties have settled to work together in initiating a program and that each party has a clearly defined role and say in how the enactment occurs.

(Balgescu and Young, 2005). Under the PPP contracts, both parties share assets for the development of infrastructure and facilities for the benefit of the general public. In addition to the sharing of assets, each party shares the potential threats and rewards associated with the investment in a particular program (Cruz \& Marques, 2013).

Through this plot, the government has endowed the private sector with the obligation of planning, financing, building, and working with public entities. As indicated by Yescombe (2011) private sector organizations have a more noteworthy aptitude for the management of complex ventures, are proficient in conveying them on time and budget. In addition, private entities are capable of maintaining and improving the performance. In this manner, PPP is considered as a compelling way to improve venture profitability through administrative proficiency and creative abilities from business practice.

Every country's approach to PPP to achieve the policy objectives of its government and to enhance the quality of basic services to the general public. PPPs for the betterment of the better health services of the general public can apply to a variety of activities. For instance, major infrastructural changes to providing support services such as lab analysis, up to the management of a hospital or building and maintaining a network of hospitals and clinics. The three most common models for hospital PPPs are PFI (Private Finance Initiative) Model, OS (Organization Social) Model and Concession Model (Kinlaw, 2008). The details of three models are given below:

\section{PFI Model}

PFIs commonly include government giving contracts to private organizations for the development and support of hospitals and related facilities, with installments spreading equitably for a long period of time over 20 to 30 years. The PFI model is perfect for land ventures where the government has ceaselessly underfunded the infrastructure and equipment. PFIs can be a vehicle for government sector to work with the private division in a politically acceptable way. A noteworthy advantage is equitable cost dissemination over a long time period. However, the PFI model is very weak as a means to implement true reform as the emphasis is on new facility development. In PFI model, the service delivery component remains under public control (Kinlaw, 2008).

\section{OS Model}

The OS model is a type of management where infrastructure and facilities (new) are provided by the government, and service delivery, including all work of therapeutic and support staff, is contracted to a non-profit association. This model has various characteristic qualities including giving full control to the contracted party over managing the workforce and full control over buying (Kinlaw, 2008).

\section{Concession Model}

Concession model is basically a coordination of the two models above, including either development (or redesign), and operation of a medical facility. The key quality of the concession model is that the private supplier's price $t$ commonly satisfies the venture needs. Like the OS Model, the concession model considers full control over staff and full control over buying. However, the concession model is the most politically 
troublesome to execute (Kinlaw, 2008).

With every model of PPPs, there are some key challenges involved. These may include lack of ability of government to enforce contracts with the private sector, a restricted pool of solid bidders as there are only a couple of worldwide hospital management organizations and no availability of local suppliers with operational experience, political risk that another/ new political party may not value working in collaboration with the private sector, funding risk that payments get delayed and cause liquidity issues etc. (Pasha \& Nasar, 2003).

However, PPPs, if implemented by addressing the pre-requisites can yield certain benefits as PPP is an arrangement where both parties-public and private are responsible for designing, financing and managing public facilities for a time period of 20-30 years (Sapri et al., 2016). The ultimate objective is to achieve Value for Money (VFM) that is the combination of costs, benefits, risks, and quality of services provided. VFM is based not only on the minimum purchase price but also on the maximum efficiency and effectiveness of the purchase (Akintoye, Beck, \& Hardcastle, 2008). PPPs also contribute by guaranteeing the sustainability of projects by improving the abilities of local associations, and by expanding the community's approach to the capability and proficiencies of the private sector. Through PPPs, the reach of the health interventions extends to a wide range of population (through national healthcare programs) and project costs are shared through additional contributions of associated partners which generally would be past the reach of implementers (Goel, Galhotra, \& Swami, 2006).

\section{Hypotheses development}

The model is adapted from Marshall and Hays (1994). The dimensions are patient care, technical quality, financial aspects, doctor's behavior and convenience provided to the patient. The dimensions are observed variables while Performance of public-private partnership is evaluated as the latent variable.

Patient care is reflecting the medical care that patient is receiving including minimum waiting time, treating a patient with respect, a thorough examination of the patient and explaining the reasons for any tests or medicines prescribed. Technical quality includes the infrastructure, diagnosis facilities and quality of doctors. Financial aspects refer to whether there is an additional financial burden on the patient or the facilities provided in the hospital are sufficient enough to cover the needs of the patients. Doctor's behavior with the patients is the key to providing quality service to the patients. The last dimension is easy accessibility for the patient to the services offered by the hospital.

The conceptual model is presented in Figure 1.

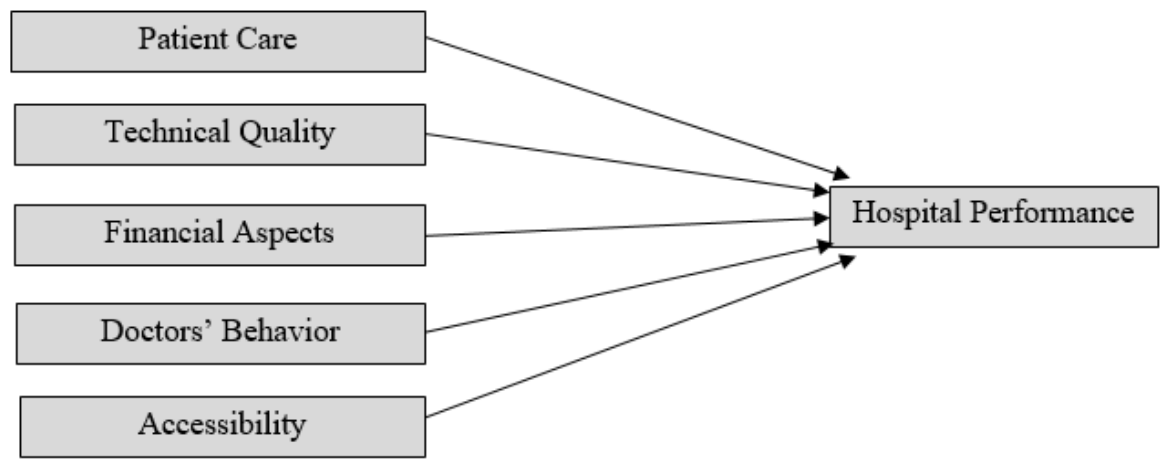

Figure 1. The Conceptual Model

Adopted from Marshall and Hays (1994)

\section{Hypotheses}

The hypotheses for the study are devised as under:

H1: Patient care has a positive and significant impact on hospital performance.

$\mathrm{H} 2$ : Technical quality has a positive and significant impact on hospital performance.

H3: Financial aspects has a positive and significant impact on hospital performance.

H4: Doctors' behavior has a positive and significant impact on hospital performance.

H5: Accessibility has a positive and significant impact on hospital performance.

\section{Methodology}

The population for this study consist of the hospitals working on a public-private partnership in Pakistan. There are over hundred hospitals working under public-private partnership. For this study, a sample of eight hospitals from four provinces of Pakistan was approached for data collection. The provinces include Punjab, Khyber Pakhtun Kha, and Baluchistan. This is a limitation to visit only eight hospitals as the approach to remote areas is difficult and also expenses of data collection will go beyond the resources.

The selected hospitals were visited to gather data. A questionnaire was designed for this study. Patients of 
the hospitals were approached and were requested to fill in the questionnaire voluntarily. As the total population was unknown so the sample size was calculated using the available online free calculator with $95 \%$ level of significance and 5\% margin of error (Hulley, Steven, Browner, Grady, and Newman, 2001). According to the formula, 384 respondents were appropriate for data collection. Therefore, a total of 384 questionnaires were distributed to collect the data. While collecting data, both indoor and outdoor patients were included in the sample. The following Table 1 presents the details of selected hospitals for this study.

Table 1 Hospitals Working under Public-Private Partnership Selected

\begin{tabular}{clll}
\hline Sr. No. & Hospital Name & \multicolumn{1}{c}{ City } & \multicolumn{1}{c}{ Province } \\
\hline 1 & Ayub Hospital & Abbottabad & KPK \\
2 & Civil Hospital & Quetta & Baluchistan \\
3 & District Headquarter Hospital & Sahiwal & Punjab \\
4 & District Headquarter Hospital & Zhob & Baluchistan \\
5 & Jinnah Hospital & Lahore & Punjab \\
6 & Khalifa Gul Nawaz Teaching Hospital & Bannu & KPK \\
7 & Lady Wallington Reading Hospital & Peshawar & KPK \\
8 & District Headquarter Hospital & Khuzdar & Baluchistan \\
\hline
\end{tabular}

The collected data from the above-mentioned hospital was entered into Microsoft Excel for data analysis. This excel file was used to apply statistical tests using SPSS and AMOS. The tests included reliability analysis, descriptive statistics, exploratory data analysis, correlation, and regression.

\section{Data Analysis}

\section{Reliability}

Table 2 Reliability

\begin{tabular}{lcc}
\hline Factors & Cronbach's Alpha & Number of Items \\
\hline Patient Care & 0.95 & 4 \\
Technical Quality & 0.55 & 3 \\
Financial Assistance & 0.85 & 3 \\
Doctors' Behaviour & 0.66 & 3 \\
Accessibility & 0.94 & 4 \\
Performance & 0.92 & 2 \\
\hline
\end{tabular}

To check the reliability of questions and scales, Cronbach Alpha text was the results shows the high validity of scales and data except for the factor technical quality (0.55) and Doctor's behavior. For patient care, performance and accessibility the results are highly satisfied with the Alpha value of more than 0.90.

\section{Descriptive Statistics}

Data was collected from 8 different hospitals across Pakistan. 12\% responses were taken from Ayub Hospital, 20\% from Civil Hospital, 9.60\% from District Headquarters Hospital Sahiwal, 20\% from District Headquarters Hospital Zhob, 3.60\% from Jinnah hospital, 12.80\% from Khalifa Gul Nawaz Teaching Hospital, 10.00\% from Lady Wallington reading Hospital and 12\% from District headquarter Hospital Khuzdar.

Responses were taken from eight different cities of Pakistan. 12\% responses were from Abbottabad, 20\% from Quetta, 9.60\% from Sahiwal, 20\% from Zhob, 3.60\% from Lahore, $12.80 \%$ from Bannu, 10\% from Peshawar and $12 \%$ from Khuzdar.

Above demographics are showing that the data were collected from various clusters to have more generalized data and to increase the validity of results. $14 \%$ responses were taken from Punjab, $35 \%$ from Kpk and $50 \%$ from Baluchistan. $49.40 \%$ respondents were male patients and $50.60 \%$ was taken from indoor and outdoor female patients.

$16.20 \%$ patients were under age group from $21-25$ years, $14.40 \%$ from $26-30$ years of age, and $20.20 \%$ from $31-35$ years of age, $23 \%$ from $36-40$ years of age, $12.60 \%$ from $41-45$ years of age, $7.60 \%$ from $46-50$ years of age and $3.80 \%$ from $51-55$ years of age.

It was also kept in mind that the responses should be from various educational stratum. 11\% patients are masters qualify, $17 \%$ are bachelors qualify, $15 \%$ were intermediate qualify, $25.20 \%$ were matriculation qualify and $32.30 \%$ were under matriculation qualify.

Data was taken equally from rural and urban areas; $56.8 \%$ from rural areas and $43.20 \%$ from urban because rural and urban patients have a different perspective of hospital performance.

\section{Correlation}

The coefficient of correlation was calculated which depicts significant relation between independent variables and dependent variable. Results are quite astonishing because it shows negative relations between two independent variables which were proposed positive in the model. Significant correlations between independent variables were also found which a disturbing factor is. The researcher needs to revise the proposed model, should collect the more data or maybe the scales and questions need to be changed. These results are demanding a 
multivariate model.

The coefficient correlation between Patient care and performance is $0.929,0.880$ between Financial assistance and performance, 0.926 between accessibility and performance, -0.861 between technical quality and performance and -0.776 between doctors behavior and performance. These results are against our prepositions. We need to change our data and collect responses again. The other correlations are also showing covariance among independent variables.

Table 3 Correlation Matrix

\begin{tabular}{llrcccc}
\hline Sr. No & Constructs & $\mathbf{1}$ & $\mathbf{2}$ & $\mathbf{3}$ & $\mathbf{4}$ & $\mathbf{5}$ \\
\hline 1 & Patient Care & 1 & & & & \\
2 & Technical Quality & $-.891^{* *}$ & 1 & & & \\
3 & Financial Assistance & $.915^{* *}$ & $-.871^{* *}$ & 1 & & \\
4 & Doctors Behaviour & $-.788^{* *}$ & $.794^{* *}$ & $-.756^{* *}$ & 1 & 1 \\
5 & Accessibility & $.939^{* *}$ & $-.896^{* *}$ & $.917^{* *}$ & $-.772^{* * *}$ & 1 \\
6 & Performance & $.929^{* *}$ & $-.861^{* *}$ & $.880^{* *}$ & $-.776^{* *}$ & $.926^{* *}$ \\
\hline$* *$
\end{tabular}

**. Correlation is significant at the 0.01 level (2-tailed).

Path analysis diagram was also made via SEM and CFA

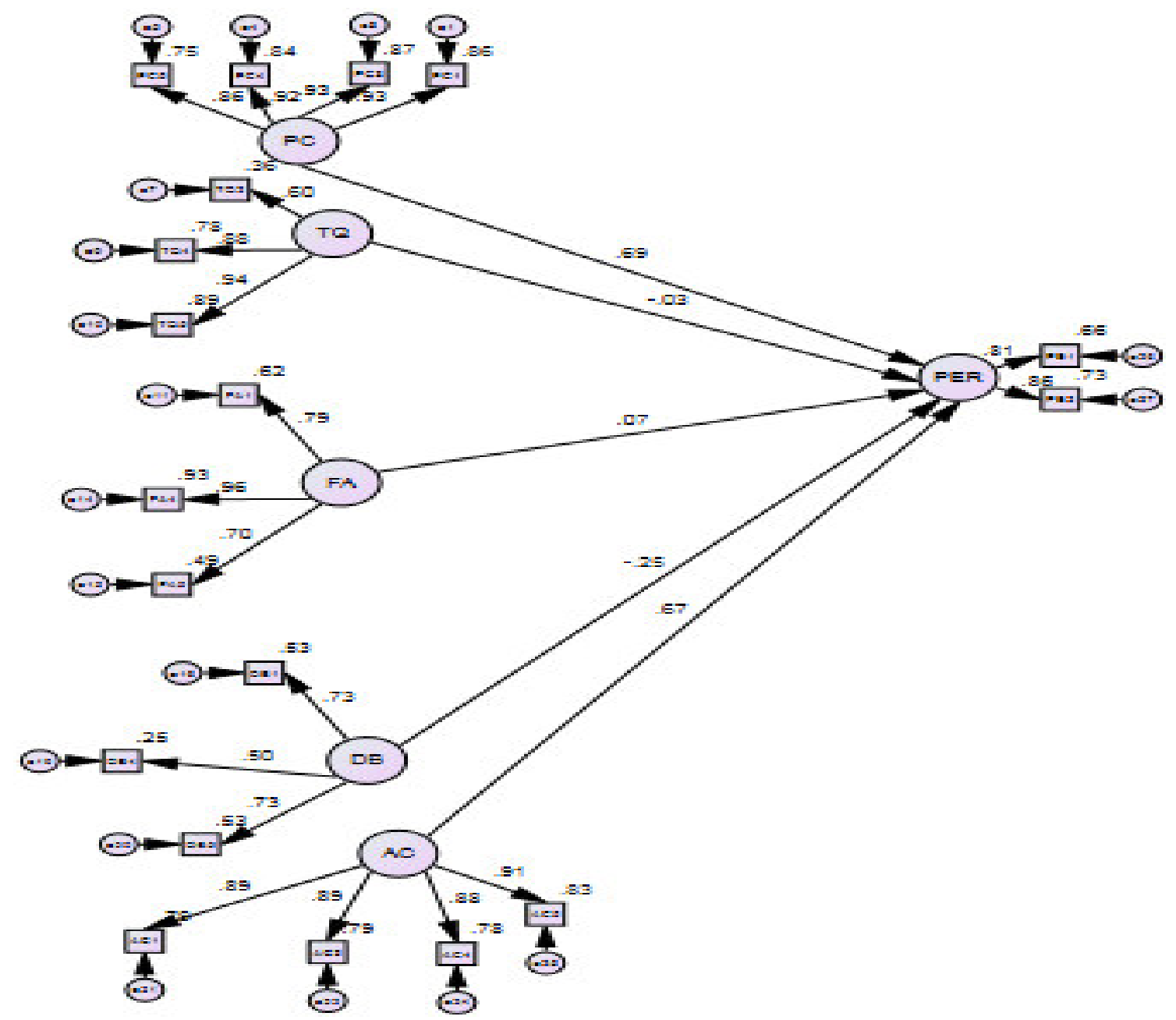

Figure 1-AMOS Results

\section{Model Fit Indicators}

Table 13-Model Fit Indicators

\begin{tabular}{|c|c|c|c|c|}
\hline RMSEA & GFI & CFI & DF & Chi Square \\
\hline 0.246 & 0.512 & 0.623 & 148 & 4618 \\
\hline
\end{tabular}




\section{Regression Estimates}

Table 14-Regression

\begin{tabular}{|c|c|}
\hline & Regression Estimate \\
\hline PER <--- PC & $.69 * * *$ \\
\hline PER <--- TQ & -.03 \\
\hline PER <--- FA & .07 \\
\hline PER <--- DB & $-.25 * * *$ \\
\hline PER <--- AC & $.67 * * *$ \\
\hline
\end{tabular}

The overall fitness model was analyzed the goodness fit index (GFI), comparative fit index (CFI) and root mean square error of approximation. GFI score is 0.512 which shows the model is a too fit. GFI value more 0.70 is considered as satisfactory. The lowest value is because of negative correlations results of 2 variables. CFI value is 0.623 which says mode is fit.

The RMSEA value should be less than 0.05 (level of significance). Here the RMSEA value is 0.246 which is not acceptable. We need to change the data or apply some tools for data. Confirmatory factor analysis (CFA) was used to explain variables. The value of RMSEA and GFI are not acceptable and has a good fit.

Path analysis diagram was also made via SEM and CFA. Regression estimates for patient care and accessibility are showing significant results and supporting our hypothesis 1 and 5 .

Result for doctors behavior are also significant but shows negative results which are against both alternative and null hypothesis for this variable.

The results for technical quality and financial aspects are not significant overall every analysis is showing a negative result which doesn't support the proposal mode.

\section{Discussion}

The current study aimed to examine the impact of five elements of Marshal and Hays model to the performance of hospitals working under PPP. The findings of the present research reveal that patient care and accessibility of patients to the hospital and its service are detrimental have a positive and significant impact on the performance of hospitals working under PPP whereas doctor's behavior shows the significant but negative impact on hospital performance. Although, the findings of the current research claimed that the availability of financial assistance and high quality of technical service is not sufficient for improving the hospital performance. The results of the present study have significant theoretical and practical implications.

\section{Theoretical Implications}

We adopt Marshal and Hays model to evaluate the performance of hospitals established under public-private partnership. The three elements of Marshal and Hays model (out of five) i.e. patient care and accessibility proved to be the significant predictor for the improvement of hospital performance. The significant impact of Marshal and Hayes model on hospital performance shows that future researchers should identify and examine other factors that lead to improves hospital performance working under PPP.

Moreover, the results of the present research show no significant impact on financial assistance and technical quality on the hospital performance. Although, financial assistance and technical quality are the two most important element of Marshal and Hayes model. So the future researchers should identify the underlying reason for the insignificance of these two elements.

In addition, the findings of the current research show that doctor's behavior indicate the significant but negative impact on hospital performance. Future researchers should examine the underlying factors that why doctor's behavior negatively influence hospital performance.

\section{Practical Implications}

Along with the theoretical implications, the findings of the current study has practical relevance as well. The results of the currents study highlight several points that assist Govt. health ministry and policymakers to make plans for the betterment of health facilities to the public. Based on the outcome of the current study, we make certain suggestions to the concerned departments.

First, Health department and policymakers should offer special training courses and sessions to medical staff to train them for the improvement of patient care. The behavior of doctors with the patients has a positive and highly significant impact on the hospital performance. In Pakistan, doctors faced the issue of work-life balance due to long working hours. Almost, all of the doctors work for more than 100 hours per week as only one doctor is available for a population of 10,000 people. Such type of hectic routine negatively influences the mental and physical health of doctors. Therefore, we suggest policymakers that they should make a plan to increase the number of doctors. As sufficient numbers of doctor to reduce workload.

Moreover, Govt. should make a long-term plan for the delivery of high-quality health services to remote areas. As the accessibility of hospitals to the patients increase the hospital performance. 


\section{Limitations and Future Direction}

The findings of the present study have significant theoretical and practical implications. Stil it is not free from limitation. The questionnaire was used to collect the data that give rise to self-reporting bias. Future researchers can eliminate the biasness occur due to self-reporting by collecting data through observations. Secondly, the current study was cross-sectional in nature. So to generalize the findings of the study, future researchers collect the data in different time periods. Moreover, the findings of the current study recommend future researchers to use other research designs as well. For instance, conduct experimental design or collect data through interviews.

\section{References}

Akintoye, A., Beck, M., \& Hardcastle, C. (2008). Public-private partnerships: managing risks and opportunities: John Wiley \& Sons.

Barlow, J., Roehrich, J., \& Wright, S. (2013). Europe sees mixed results from public-private partnerships for building and managing health care facilities and services. Health Affairs, 32(1), 146-154.

Blagescu, M., \& Young, J. (2005). Partnerships and Accountability: Current thinking and approaches among agencies supporting Civil Society Organisations: Overseas Development Institute.

Cruz, C. O., \& Marques, R. C. (2013). Infrastructure public-private partnerships: Springer.

Goel, N., Galhotra, A., \& Swami, H. (2006). Public-Private Partnerships In The Health Sector. The Internet Journal of Health, 6(2), 1-5.

Hulley, S. B., Steven R, C., Browner, W. S., Grady, D. G., \& Newman, T. B. (2001). Designing Clinical Research (Second ed.): Lippincott Williams and Wilkins.

Kinlaw, H. (2008). Public-private investment partnerships in health systems strengthening. Paper presented at the Report on Wilton Park Conference.

Marshall, G. N., \& Hays, R. D. (1994). The patient satisfaction questionnaire short-form (PSQ-18): Rand Santa Monica, CA.

Pasha, H. A., \& Nasar, A. (2003). Public-Private Partnership in the Health Sector: Evidence From A Developing Country.

Sapri, M., Hariati, A., Ting, L. S., \& Sipan, I. (2016). Public-Private Partnership Benefits in Delivering Public Facilities in Malaysia. Paper presented at the MATEC Web of Conferences.

Savas, E. S., \& Savas, E. S. (2000). Privatization and public-private partnerships: Chatham House New York.

Yescombe, E. R. (2011). Public-private partnerships: principles of policy and finance: Butterworth-Heinemann. 